\title{
STRATEGI PENGEMBANGAN EKONOMI LOKAL MELALUI KAWASAN DESA WISATA BERBASIS KOMODITAS UNGGULAN KOPI LIBERIKA (KBA) DI DESA KUMPAI BATU ATAS KECAMATAN ARUT SELATAN KABUPATEN KOTAWARINGIN BARAT
}

\author{
LOCAL ECONOMIC DEVELOPMENT STRATEGY THROUGH A TOURISM \\ VILLAGE AREA BASED ON THE LEADING COMMODITY OF LIBERIKA \\ COFFEE (KBA) IN KUMPAI BATU ATAS VILLAGE ARUT SELATAN DISTRICT \\ KOTAWINGIN BARAT REGENCY
}

\author{
Noor Rizkiyah*, Shofiyah \\ Agribisnis Universitas Antakusuma Pangkalan Bun \\ *E-mail: rizkiyahni74@gmail.com \\ (Diterima 18-06-2021; Disetujui 16-07-2021)
}

\begin{abstract}
ABSTRAK
Pengembangan ekonomi lokal melalui konsep desa wisata yang berbasis komoditas pertanian merupakan wujud dari suistanable economy, yaitu tidak hanya menciptakan peluang usaha berbasis pengembangann produk pertanian, namun juga terkait dengan pemberdayaan masyarakat dan keberlanjutan sehingga siap berkompetitif di pasar global. Penelitian ini bertujuan untuk mengetahui keunggulan Desa Kumpai Batu Atas Kecamatan Arut Selatan Kabupaten Kotawaringan Barat dalam mengembangkan kopi liberika KBA, menggunakan metode kualitatif deskriptif dengan pendekatan SWOT. Berdasarkan pada penentuan faktor internal dan eksternal yang kemudian digabungkan sehingga dapat dirumuskan 1) Peningkatan produktivitas lahan untuk budidaya kopi liberika melalui dukungan kelompok dan pemerintah setempat dengan penciptaan konsep desa wisata berbasis produk pertanian untuk mendorong peningkatan ekonomi local, 2) Optimalisasi kegiatan budidaya dengan penciptaan nilai tambah melalui penguatan modal, 3) Peningkatan pengetahuan petani kopi yang berwawasan teknologi dan pemerintah daerah sebagai penyedia teknologi tepat guna agar kopi liberika KBA mampu berdaya saing, dan .4) Pengembangan teknologi berkelanjutan dalam pemberantasan organisme pengganggu tanaman dan pemerintah daerah mewujudkan adanya klaster wilayah berdasarkan kesesuaian lahan.
\end{abstract}

Kata kunci : Kopi liberika, keberlanjutan, modal, daya saing, pasar global

\section{ABSTRACT}

The development of the local economy through the concept of a tourism village based on agricultural commodities is a manifestation of a sustainable economy, which is not only creating business opportunities based on the development of agricultural products but also related to community empowerment and sustainability so that they are ready to be competitive in the global market. This study aims to determine the advantages of Kumpai Batu Atas village, South Arut sub-district, West Kotawaringan Regency in developing KBA liberika coffee, using descriptive qualitative method with SWOT approach. Based on the determination of internal and external factors which are then combined so that it can be formulated 1) Increasing land productivity for liberika coffee cultivation through the support of groups and local governments by creating a tourism village concept based on agricultural products to encourage local economic improvement 2) Optimizing cultivation activities by creating added value through strengthening capital 3) Increasing knowledge of technology-minded coffee farmers and local governments as providers of appropriate technology, so that KBA liberika coffee is able to be competitive. 4) Development of sustainable technology in eradicating plant-disturbing organisms and local governments to create regional clusters based on land suitability.

Keywords : Liberica coffee, sustainability, capital, competitiveness, global market 


\section{PENDAHULUAN}

Pembangunan berkelanjutan atau dikenal sebagai Sustainable Development Goals (SDGs) merupakan program dengan 17 tujuan dengan 169 capaian yang terukur dengan waktu yang telah ditetapkan oleh PBB yang bertujuan untuk kepentingan manusia dan keselamatan bumi. Tujuan menghapus kemiskinan dan mengakhiri kelaparan yang terdapat pada tujuan utama SDGs menjadi tanggung jawab pemerintah dalam mewujudkan peningkatan perekonomian melalui penyelenggaraan pembangunan secara cepat dan tepat. Ekonomi lokal merupakan pengejawentahan dari otonomi daerah (kabupaten/kota) dalam proses mengembangkan kemampuannya untuk produksi, alokasi dan distribusi berbagai sumber daya yang dimilikinya agar menjadi produk unggulan yang dapat berdaya saing di tingkat regional, nasional, interrnasional bahkan global.

Konsep pengembangan ekonomi lokal adalah menggali dan mengembangkan potensi-potensi sumber daya di wilayah tersebut untuk meningkatkan pembangunan ekonomi lokal. Pendekatan konsep pengembangan ekonomi lokal memberikan kesempatan atau peluang kepada masyarakat untuk berperan aktif dan inovatif dalam menentukan dan mengelola sumber daya lokal yang tersedia baik sumber daya alam maupun sumber daya manusia sebagai mata rantai perekonomian.

Dengan pengembangan ekonomi lokal maka roda perekonomian daerah akan berjalan karena terdapat kegiatan produksi yang berdampak pada tersedianya lapangan kerja yang diharapkan mampu menyerap tenaga kerja, sehingga terjadi peningkatan perekonomian setempat, kondisi ini menjadikan suatu wilayah mampu bersaing dan mengurangi disparitas wilayah. Menurut Barkley (1994), tujuan utama dari pengembangan ekonomi lokal adalah menciptakan dan meningkatkan jumlah dan jenis lapangan pekerjaan yang disesuaikan dengan keterampilan dan keahlian masyarakat lokal.

Pertumbuhan ekonomi Kabupaten Kotawaringin Barat dari sektor pertanian sebesar 26,06\% terhadap PDRB dan produk kelapa sawit memberikan kontribusi sebesar $6,3 \%$ meskipun potensi tertinggi adalah tanaman kelapa sawit namun saat ini tanaman perkebunan yang juga menjadi perhatian pemerintah dan masyarakat adalah tanaman kopi walaupun kopi sudah ada sejak program transmigrasi dicanangkan,. 
Desa Kumpai Batu Atas (KBA) di Kecamatan Arut Selatan Kabupaten Kotawaringin Barat merupakan salah satu wilayah yang memiliki potensi pengembangan budidaya kopi liberika yang memanfaatkan lahan pekarangan masyarakat untuk dijadikan kebun kopi. Kopi liberika KBA ini memiliki keunikan tersendiri karena memiliki aroma buah nangka. Kondisi ini seiring dengan berubahnya pola preferensi konsumen dalam menikmati kopi, konsumen menuntut adanya sudut-sudut lokasi yang memiliki view dan sarana edukasi. Laksana gayung bersambut karena petani kopi mengalami kendala dan kesulitan dalam menjual kopi dan harga jual kopi yang rendah maka sejak tahun 2017 sebagian masyarakat desa Kumpai Batu Atas berusaha membuat konsep desa wisata berbasis tanaman kopi liberika yang diinisiasi oleh kelompok tani dan LSM Kelompok Sadar Wisata agar dapat mengurangi praktek beralihnya petani ke komoditas lain dan diharapkan dapat berkontribusi pada PDRB.

Kopi liberika memiliki ciri daun lebar dan buahnya besar seluruh masyarakat membudidayakan jenis kopi liberika pada kebun-kebun sekitar rumahnya. Kopi liberika adalah salah satu jenis kopi di Indonesia yang produksinya kurang dari $1 \%$ dari total produksi kopi dari berbagai jenis atau species, yang paling mendominasi adalah kopi robusta yang mencapai $73 \%$ dan $27 \%$ kopi arabika.

Saat ini terdapat 32 kebun warga (Borneo.news, 2018) yang digunakan untuk budidaya kopi liberika KBA. Produksi kopi liberika di desa Kumpai Batu Atas jika didasarkan pada jumlah pohon kopi yang diusahakan dengan hasil $20 \mathrm{~kg}$ per 90 pohon saat ini di desa Kumpai Batu Atas mengusahakan 2000 pohon kopi liberika maka produksinya mencapai $500 \mathrm{~kg} /$ panen.

Meskipun secara regional telah memberikan peningkatan pendapatan masyarakat sekitar, namun maraknya kegiatan alih fungsi lahan menyebabkan menurunnya lahan-lahan perkebunan tanaman kopi. Oleh karena itu, kajian ini bertujuan untuk merumuskan strategi pengembangan ekonomi lokal berbasis komoditas unggul kopi liberika untuk meningkatkan perekonomian dan kesejahteraan masyarakat, khususnya petani kopi liberika di Desa Kumpai Batu Atas Kecamatan Arut Selatan.

\section{METODE PENELITIAN}

Penelitian ini menggunakan pendekatan kualitatif, yaitu penelitian 
yang temuan-temuannya tidak diperoleh melalui prosedur kuantifikasi seperti perhitungan statistic (Rukajat, 2018), sedangkan menurut Silalahi (2012) kualitatif merupakan serangkaian data hasil observasi sehingga tujuan dari kualitatif menekankan pada cakupan informasi tentang fenomena utama yang dieksplorasi dalam penelitian, partisipan penelitian dan lokasi penelitian.

Jenis penelitian ini adalah penelitian deskriptif yang diartikan sebagai prosedur atau cara memecahkan masalah penelitian dengan memaparkan keadaan objek yang diselidiki sebagai mana berdasarkan fakta-fakta yang aktual pada saat sekarang. Lokasi penelitian ditentukan secara purposif yaitu di Desa Kumpai Batu Atas

Berdasarkan tujuan penelitian, maka cara yang dilakukan yaitu mengidentifikasi faktor internal dan faktor eksternal yang mempengaruhi kegiatan pengembangan ekonomi lokal. Kemudian dilakukan tahap penggabungan dengan menggunakan analisis SWOT yang dikomparasikan dengan kondisi yang diinginkan dalam kegiatan pengembangan ekonomi lokal.

\section{HASIL DAN PEMBAHASAN}

\section{Potensi Subsektor Perkebunan Kopi}

\section{a. Produksi Kopi}

Indonesia adalah negara penghasil kopi terbesar pada tahun 2015 dan menduduki peringkat keempat di dunia. Urutan pertama adalah negara Brazil dengan total produksi mencapai 3.300.000 ton, urutan kedua Vietnam dengan produksi sebesar 1.530 .000 ton dan urutan ketiga adalah Kolombia dengan produksi mencapai 840.000 ton dan Indonesia total produksi mencapai 600.000 ton (FAOSTAT, 2016).

Pada tahun 1997-2017 kondisi perkembangan industri kopi di Indonesia khususnya jumlah produksi yang dihasilkan cukup memuaskan, namun produksi di lapangan terlihat fluktuatif. Tidak stabilnya produksi kopi di Indonesia menurut Ditjen Perkebunan disebabkan umur tanaman yang sudah tua, tidak produktif, rusak dan akibat hama penyakit dan organisme pengganggu. Selain itu, mesin proses produksi kopi sudah terlalu tua.

\section{b. Perkembangan Ekspor Kopi}

Pada tahun 2018 volume ekspor kopi terbesar adalah arabika, robusta yang tidak diroasted dan dihilangkan kafeinnya sebesar 97,7\% dari total ekspor. Sedangkan kopi selain jenis tersebut tidak 
diroasted dan tidak dihilangkan kafeinnya sebesar $1,12 \%$; dan kopi sangrai tanpa kafein 0,96\%. Ekspor kopi selama delapan tahun terakhir cenderung berfluktuasi, yaitu berkisar antara 30,46\% hingga 40,15\%. Pada tahun 2011 total volume ekspor mencapai 346,49 ribu ton dengan total nilai sebesar US\$ 1036,67 juta menurun menjadi 279,96 ribu ton pada tahun 2018 dengan total nilai sebesar US\$ 815,93 juta (Pusdatin,2018)

\section{c. Perkembangan Konsumsi Kopi}

Berdasarkan Internasional Coffe Organization (2017), pada tahun 2015 menunjukkan tren kenaikan konsumsi kopi Indonesia. ICO merilis data pertumbuhan jumlah peminum kopi di Indonesia yaitu sebesar 8\% lebih besar daripada pertumbuhan dunia yang mencapai $6 \%$. Selaras dengan ICO data Survei Sosial Ekonomi Nasional (SUSENAS) oleh BPS SUSENAS menunjukkan permintaan kopi di rumah tangga untuk keperluan konsumsi adalah kopi bubuk/kopi biji. Namun pada periode 2002-2016 konsumsi kopi per kapita mengalami kecenderungan menurun ditunjukkan dengan adanya penurunan 1,66 per tahun. Di tahun 2002 turun sebesar 1,29 kg/kapita/tahun hingga di tahun 2016 turun hingg 32,93\% yaitu sebesar $0,871 \mathrm{~kg} / \mathrm{kapita} / \mathrm{tahun}$ dan selama periode tersebut kenaikan hanya terdeteksi di tahun 2015 yaitu sebesar $1,35 \mathrm{~kg} / \mathrm{kapita} /$ tahun atau naik dari 2014 sebesar $0,89 \mathrm{~kg} / \mathrm{kapita} /$ tahun atau naik sebesar $33,51 \%$.

\section{d. Desa wisata}

Berdasarkan UU No. 9 Tahun 2010 terkait kepariwisataan tepatnya pada pasal 30 a-k mengatur kewenangan pemerintah daerah; salah satunya adalah menyelenggarakan serta mengatur pariwisata di wilayahnya dan mengadakan kelompok masyarakat sadar wisata. Dengan melihat kewenangan tersebut, maka konsep desa wisata menjadi alternative. Desa wisata menurut (Ida Ketut S, 2010) merupakan kawasan pedesaan yang mempunyai berbagai macam karakteristik tertentu yang menjadi tujuan wisata. Biasanya penduduknya masih memiliki kekhasan, seperti memiliki makanan khas, model pertanian dan bentuk sistem sosial dan faktor alam yang tetap terjaga sehingga turut mendukung wilayah desa wisata.

\section{e. Pengembangan Ekonomi Lokal (PEL)}

Pengembangan ekonomi lokal (PEL) adalah proses dimana pemerintah dan masyarakat lokal bekerjasama untuk merangsang, mendorong dan memelihara 
aktivitas usaha dalam rangka penciptaan lapangan pekerjaan (Blakely, 1994).

Teori PEL sendiri mengemukakan beberapa pertanyaan seperti bagaimana mengembangkan perekonomian lokal dengan memanfaatkan potensi sumber daya yang dimiliki, sejauh mana industri tersebut berperan menciptakan lapangan kerja bagi masyarakat setempat serta bagaimana untuk keberlanjutannya dimasa depan (Blair, 1995).

\section{Faktor Kekuatan Aspek Strategi Internal}

\section{Potensi Sumber Daya Alam}

Desa Kumpai Batu Atas memiliki luas wilayah $30.000 \mathrm{~m}^{2}$ yang merupakan $1,25 \%$ dari total luas Kecamatan Arut Selatan. Dengan ketinggian $12 \mathrm{mdpl}$, beriklim panas dan lembab serta memiliki curah hujan $3000 \mathrm{~mm}^{3}$ per tahun, Kumpai Batu Atas merupakan 1 dari 13 desa yang ada di Kecamatan Arut Selatan. Dengan dukungan topografi dan iklim tersebut menjadikan desa Kumpai Batu Atas berpotensi untuk membudidayakan berbagai jenis tanaman, sebagian besar masyarakat setempat adalah petani. jumlah penduduknya mencapai 3.037 jiwa atau $2,57 \%$ dari total penduduk di Kecamatan Arut Selatan. Dengan rasio penduduk laki-laki lebih banyak dari jumlah penduduk perempuan yaitu 1.557 jiwa penduduk laki-laki dan 1.505 jiwa penduduk perempuan (BPS, 2018).

Desa Kumpai Batu Atas tergolong desa swasembada (self suppporting) dengan memanfaatkan potensi sumber daya alam desa yang beragam dan salah satunya kopi, kondisi ini dapat dilihat dari perkembangan jumlah pembudidayaan tanaman kopi yang terus meningkat dari tahun ke tahun dengan penambahan jumlah pohon yang produktif.

\section{Keunggulan Kopi Liberika KBA}

Kopi Liberika adalah salah satu tanaman perkebunan yang dapat tumbuh dan berproduksi dengan baik di lahan gambut sehingga berpotensi menjadi komoditas unggulan daerah.

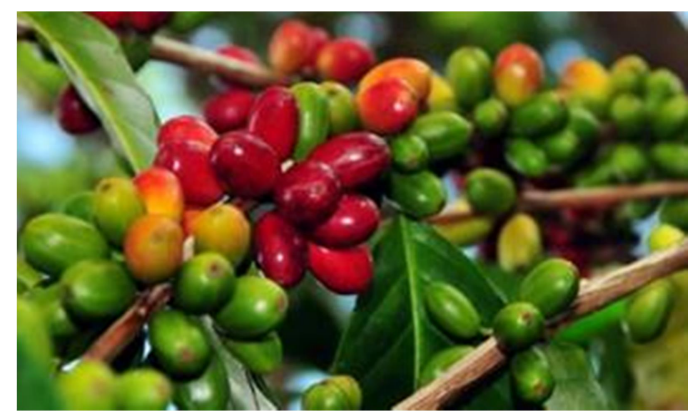

Gambar 1. Tanaman Kopi Liberika

Dengan cita rasa buah nangka after taste maka kopi liberika berbeda dengan jenis kopi yang banyak dibudidayakan lebih luas di Indonesia seperti kopi robusta dan arabika. Dengan aroma dari kopi Liberika yang khas, ditambah 
dengan rasa pahit yang lebih kental, sehingga masyarakat setempat mengenal sebagai kopi nangka. Selain karena aroma yang tajam, juga karena bijinya besar hampir $2 \mathrm{x}$ lipat dari biji robusta atau arabika, dan bisa dikenali dari pohon kopinya yang dapat tumbuh hingga mencapai ketinggian 9 meter. Kopi Liberika memiliki masa panen yang hampir merata di sepanjang tahun, puncaknya terjadi dua kali dalam setahun. Dengan demikian untuk memenuhi permintaan konsumen kopi liberika KBA, petani desa Kumpai Batu Atas diyakini dapat memenuhinya karena dengan 2.000 pohon yang saat ini sedang diusahakan oleh petani dapat menghasilkan hampir $500 \mathrm{~kg} /$ panen.

Untuk meningkatkan nilai jual, masyarakat berusaha memberikan nilai tambah yang semula kopi hanya untuk dikonsumsi masyarakat namun dengan adanya berbagai upaya dan untuk memenuhi permintaan maka kopi liberika KBA yang memiliki aroma khas buah tadi dicoba dijual tidak hanya dalam bentuk green bean namun sudah dipasarkan dalam berbagai kemasan yaitu kemasan 100 gram dan 150 gram dengan harga yang bervariasi serta brand atau logo menggunakan nama desa setempat.

\section{Peran Masyarakat dan Kelompok Lokal}

Tanaman kopi liberika yang pada awalnya tidak diminati oleh masyarakat, karena dianggap tidak bernilai ekonomis sehingga banyak yang ditebang, kemudian oleh beberapa pemerhati dicoba untuk dihidupkan kembali. Adalah kelompok tani Buria Lestari dan komunitas lokal Selanting (Seruyan, Lamandau dan Tanjung Puting) dan Pokdarwis (Kelompok Sadar Wisata) yang menginisiasi untuk menghidupkan kembali tanaman kopi dengan model pengusahaan, yang mensinergikan dengan wisata edukasi. Kemudian kelompok Selanting mengadakan pendampingan pembuatan pupuk organik dari limbah kopi, kegiatan ini bertujuan untuk memberikan learning kepada masyarakat petani kopi setempat akan pentingnya keberlanjutan.

Sedangkan kontribusi pemerintah setempat ditunjukkan dengan dikeluarkan surat keputusan pembentukan pokdarwis oleh Dinas Pariwisata, yaitu SK Nomor: 556/04/Dispar-I tentang Pembentukan Kelompok Sadar wisata (Pokdarwis) Sekar Wangi Desa Kumpai Batu Atas ( Bryan, 2019). 
Faktor Kelemahan Bagian Strategi Internal

\section{Penggunaan Teknologi}

Penguasaan teknologi sebagai pendorong terwujudnya nilai tambah dalam usaha pertanian selain itu untuk meningkatkan daya saing. Kemampuan dalam memanfaatkan, mengembangkan dan menguasai teknologi masih belum memadai. Hal ini dipicu oleh masih lemahnya kesadaran serta kurangnya informasi dalam menggunakan teknologi. Rendahnya penggunaan teknologi juga dipicu oleh terbatasnya kemampuan sumber daya petani kopi liberika. Desa Kumpai Batu Atas sebagai salah satu wilayah lokasi pengembangan kopi liberika meskipun tanaman ini sudah dibudidayakan semenjak tahun 1980an. Namun kurangnya pendampingan maka terjadi penurunan produksi kopi bahkan petani beralih mengusahakan jenis tanaman lain.

\section{Faktor Eksternal}

\section{Peluang}

Faktor-faktor yang mempengaruhi peluang dalam pengembangan kopi liberika KBA adalah sebagai berikut;

\section{Alternatif Pasar Dalam Pengembangan Kopi Liberika KBA}

Sebagai pendekatan pengembangan alternatif wisata maka konsep desa wisata merupakan pilihan yang tepat dalam mengemas suatu desa menjadi wisata. Dengan formula menintegrasikan masyarakat setempat dengan ciri khas desa (Nur Indah dkk, 2015). Salah satu identifikasi masalah pada petani kopi liberika yang ada di desa Kumpai Batu Atas adalah kurangnya pangsa pasar, kopi hanya dijual di pasar tradisional atau atas dasar permintaan saja sehingga produksi kopi yang ada tidak terjual habis. Adanya peran beberapa komunitas lokal yang mengenalkan pengembangan kopi liberika melalui model wisata menjadikan peluang bagi petani kopi desa Kumpai Batu Atas dalam mengembangkan produksi kopi liberika.

\section{Peran Pemerintah Daerah}

Dalam hal pengembangan budidaya kopi, pemerintah daerah dalam hal ini Pemerintah Kabupaten Kotawaringin Barat melalui Dinas Tanaman Pangan, Hortikultura dan Perkebunan Kabupaten Kotawaringin Barat bersedia mendukung para petani dalam hal pembinaan dan pendampingan hingga mengusulkan bantuan bibit serta peralatan pengolahan kepada pemerintah provinsi maupun pusat. Meskipun pengembangan kopi liberika di desa Kumpai Batu Atas saat ini masih dalam realtif kecil, namun Dinas TPHP Kabupaten Kotawaringin 
Barat berupaya mendorong para petani agar dapat mengembangkan budidaya kopi ini lebih besar sehingga dapat meningkatkan kesejahteraan masyarakat sekitar.

\section{Ancaman}

Faktor-faktor yang mempengaruhi ancaman dalam pengembangan kopi liberika KBA di Desa Kumpai Batu Atas sebagai berikut:

\section{Alih Fungsi Lahan}

Pengalihan fungsi lahan terbagi menjadi beberapa, yaitu alih fungsi lahan dari tanaman lahan sawah ke lahan kering, lahan pertanian ke non pertanian serta lahan perkebunan ke lahan tanaman pangan atau hortikutlura. Alih fungsi lahan dipengaruhi oleh faktor eksternal dan internal, adanya dampak transformasi ekonomi seperti keberpihakan ke sektor industri dan tekanan penduduk, sedangkan faktor internal lebih pada kemiskinan yang dirasakan petani karena bergesernya faktor sosial ekonomi. Kondisi ini juga terjadi di desa Kumpai Batu Atas, ketika tanaman kopi liberika tidak memiliki nilai ekonomis maka para petani mengalihkan budidaya tanaman kopinya ketanaman pangan, hortikultura bahkan perkebunan kelapa sawit. Pohon tanaman kopi yang sudah menghasilkan, banyak yang ditebang dan beralih ke tanaman lain yang lebih menguntungkan.

\section{Serangan Organisme Pengganggu Tanaman (OPT)}

Aspek penting dalam budidaya kopi adalah perhatian terhadap serangan organisme pengganggu tanaman (OPT), baik hama dan penyakit. Hama utama yang menyerang buah kopi Liberika adalah Hypothenemus hampei atau dikenal juga sebagai penggerek buah kopi (PBKo). Budidaya kopi liberika di desa Kumpai Batu Atas juga tidak luput dari serangan PBKo. Menurut Rahayu dan Sulistyowati (2014) dalam Andre dan Doni (2018), selain PBKo, OPT yang menyerang kopi Liberika di Kalimantan Tengah antara lain kutu hijau (Coccus spp.), kutu putih (Planococcus spp.), penyakit karat daun (Hemileia vastatrix), penyakit bercak daun (Cercospora coffeicola), penyakit Septobasidium sp. dan gulma picisan (Drymoglossum phyloselliodes) walaupun dalam intensitas serangan yang rendah.

\section{Pendekatan SWOT}

\section{Strategi SO (Strenght - Opportunities)}

Dengan melihat aspek kekuatan yang dimiliki oleh desa Kumpai Batu Atas dan peluang yang ada, maka strategi SO dapat dirumuskan sebagai berikut: (1) Peningkatan produktivitas lahan 
pekarangan dan kepastian harga, (2) Meningkatkan koordinasi yang lebih baik antar lembaga baik lembaga pemerintah daerah, swasta, komunitas pemerhati, dan koperasi untuk mendukung dan mendorong pengembangan budidaya kopi liberika, (3) Model wisata edukasi berbasis komoditas lokal diperkuat dengan kebijakan dan aturan berdasarkan keputusan pemerintah setempat, dan (4) Melakukan pendampingan yang lebih intensif untuk mendorong kemandirian masyarakat petani kopi, dengan memberikan kesempatan berinovasi mengembangkan kopi liberika KBA agar dapat berdaya saing.

\section{Strategi ST (Strenght - Threaths)}

Dengan perubahan pola permintaan konsumen terhadap kopi maka strenght threaths merupakan strategi yang digunakan untuk mengoptimalkan kekuatan internal. Kekuatan potensi sumber daya alam, keunggulan kopi liberika KBA dan peran serta masyarakat dan komunitas pemerhati seyogyanya dapat meminimalkan ancaman pengembangan kopi liberika guna mendukung ekonomi lokal. Strategi yang dapat dirumuskan dengan melihat potensi kekuatan dan ancaman yang dihadapi antara lain: (1) Optimaslisasi kegiatan budidaya kopi liberika dengan mengedepankan pemahaman kepada masyarakat dan keberpihakan pemerintah daerah untuk mendukung pengembangan komoditas lokal yaitu kopi liberika, (2) Pemantauan proses dan hasil, serta pasca panen melalui evaluasi secara periodik agar mempermudah identifikasi masalah dengan melibatkan pihak-pihak terkait termasuk akademisi, dan (3) Bekerjasama dengan pihak pemodal sebagai mitra dalam penguatan modal usaha sehingga petani kopi liberika di desa Kumpai Batu Atas tetap bisa melakukan kegiatan meskiupun kondisi perekonomian tidak stabil.

\section{Stretegi WO (Weakness-Opportunities)}

Pengembangan kopi liberika di desa Kumpai Batu Atas memiliki kelemahan, namun dengan melihat peluang yang ada, menjadikan strategi weakness opporrtunities berusaha meminimumkan kelemahan internal dengan memanfaatkan peluang eksternal. Adapun stretegi WO dapat dirumuskan sebagai berikut: (1) Pengembangan teknologi tepat guna pasca penen, (2) Efisiensi dan nilai tambah sehingga dapat meningkatkan produksi kopi liberika yang mampu berdaya saing, dan (3) Pemerintah daerah memberikan kepastian dan perlindungan untuk mendukung model promosi dalam menciptkan pasar 
dengan memanfaatkan komoditas lokal yang disinergikan dengan teknologi.

\section{Strategi WT (Weakness - Threaths)}

Strategi yang digunakan dalam meminimalisir kelemahan yang ada serta menghindari ancaman eksternal. Adapun strategi WT yang dapat dilaksanakan sebagai berikut; (1) Pemanfaatan teknologi yang berwawasan lingkungan bertujuan untuk menjaga keberlanjutan usaha budidaya kopi liberika, (2) Peningkatan pengetahuan dan keterampilan baik secara formal maupun informal terkait teknologi budidaya kopi, dan (3) Klasterisasi wilayah dengan didukung analisis kesesuaian lahan.

\section{KESIMPULAN DAN SARAN}

\section{Kesimpulan}

Ekonomi lokal melalui kawasan agrowisata berbasis komoditas pertanian bertujuan untuk meningkatkan kesejahteraan dan daya saing oleh karena strategi yang dapat dirumuskan antara lain:

\section{Strategi Strenght Opportunities (SO)} dengan meningkatkan produktivitas lahan pekarangan dengan dukungan pemerintah daerah, dalam penciptaan model pasar melalui kawasan desa wisata.

\section{Strategi Strenght Threaths (ST)}

dalam memanfaatkan kekuatan untuk mencegah ancaman, dengan strategi optimaslisasi kegiatan budidaya dengan dukungan pemerintah, untuk penciptaan nilai tambah melalui penguatan modal.

\section{Strategi Weakness Opportunity (WO)} dalam mengatasi kelemahan dengan melihat peluang maka diperlukan peningkatan pengetahuan petani kopi, agar berwawasan teknologi dan pemerintah daerah sebagai penyedia teknologi tepat guna, agar kopi liberika KBA mampu berdaya saing.

4. Strategi Weakness Threats (WT) pengembangan teknologi berkelanjutan dalam pemberantasan organisme pengganggu tanaman dan meningkatkan pengetahuan masyarakat petani kopi liberika, serta keikutsertaan pemerintah daerah dalam mewujudkan klaster wilayah berdasarkan kesesuaian lahan.

\section{Saran}

Perlu adanya tambahan model kegiatan yang kreatif dan inovatif berbasis digital platform untuk meningkatkan kekuatan sehingga memiliki keunggulan komparatif dan mampu berdaya saing secara global. 


\section{DAFTAR PUSTAKA}

Blakely, E. (1994). Planning Local Economic Development (Theory and Practice). California: Sage Publication. hl 446 from http://www.researchgate.net/public ation/341989604

Badan Pusat Statistik (2017) from https://www.bps.go.id/publication/2 017/07/26/b598fa587f5112432533a 656/statistik-indonesia-2017.html

Borneo.news.(2018).Kopi Liberika di Kobar Sudah Ada Sejak 1988 from https://www.borneonews.co.id/berit a/109088-kopi-liberika-di-kobar-su dah-ada-sejak-1988 [ Diakses: 17 Oktober 2020]

D. Mawardhi, Andre, Setiadi Doni. (2018). Strategi Pemanfaatan Lahan Gambut melalui Pengembangan Agroforestri Kopi Liberika (Coffea liberica). Prosiding Lahan Sub Optimal. From http://conference.unsri.ac.id/index.p $\mathrm{hp} /$ lahansuboptimal/article/downloa $\mathrm{d} / 1219 / 635$

Dyah Wahyu Prasetyaningsih Eka, Widjonarko (2015). Strategi Pengembangan Ekonomi Lokal Berbasis Komoditas Salak di Kecamatan Madukara Kabupaten Banjarnegara. from https://ejournal3.undip.ac.id/index. php/pwk/article/view/9812

FAOSTAT (2016). Food and Agriculture Organization. from https://FAOSTATstat3.FAOSTAT. org/download/Q

Indah Nur Ariyani, Demartoto Argyo, Zuber Ahmad. (2015). Habitus Pengembangan Desa Wisata Kuwu: Studi Kasus Desa Wisata Kuwu Kecamatan Kradenan Kabupaten Grobogan. Jurnal Analisa Sosiologi Oktober, 4(2): 60 -74 .

https://www.google.com/search?q= artikel + desa + wisata\&oq $=$ artikel + de sa\&aqs $=$ chrome.1.69i57j69i59j018. 6421j0j7\&sourceid $=$ chrome \&ie $=$ UTF -8

Jaafar, M., Kayat, K., Tangit, T. M.,and Yacob, M. F. 2013. Nature-based rural tourism and its economic benefits: A case study of Kinabalu National Park. Worldwide Hospitality and Tourism Themes, 5 (4), 342-352. https://scholar.google.com/citations ?user $=$ JB5jAqoAAAAJ\&hl=en

Kecamatan Arut Selatan Dalam Angka, 2018. Badan Pusat Statistik Kabupaten Kotawaringin Barat https://kobarkab.bps.go.id/publicati on/2018/09/26/b08a84305597a4f55 6dc6d0e/kecamatan-arut-selatan-da lam-angka-2018.html

L. Djumaty Brian, Putri hayam Dey,Nina.(2020).Peran Mosal Sosial Kelompok Sadar Wisata Dalam Mengembangkan Desa Wisata Kopi Di Desa Kumpai Batu Atas, Kabupaten Kotawaringin Barat, Provinsi Kalimantan Tengah AGRISEP Vol. 19 No. 1 Maret 2020 Hal: $177 \quad-\quad 190$ https://www.researchgate.net/public ation/340316195_Peran_Modal_So sial_Kelompok_Sadar_W Wisata_dala $\mathrm{m} \_$Mengembangkan_Desa_Wisata Kopi_di_Desa_Kumpai_Batu_Ata S_Kabupaten_Kotawaringin_Barat Provinsi_Kalimantan_Tengah

Pusat Data dan Sistem Informasi Pertanian. (2018). Outlook Kopi http://epublikasi.setjen.pertanian.go .id/arsip-outlook/75-outlook-perkeb unan/632-outlook-kopi-2018

Rahayu, D.S. \& Sulistyowati, E. (2014) Organisme pengganggu tanaman kopi Liberika di Kalimantan Tengah. Warta Pusat Penelitian Kopi dan Kakao Indonesia 26(2):11-14.http://conference.unsri. ac.id/index.php/lahansuboptimal/art icle/download/1219/187 
Sastrayuda, G. (2010). Konsep Pengembangan Kawasan Agrowisata Hand Out Mata Kuliah Concept Resort And Leisure, Strategi Pengembangan dan Pengelolaan Resort And Leisure. Retrieved from UPI Website:

http://file.upi.edu.gumelar_s.go.id.

[diakses 20 November 2019]

Suwena, I Ketut (2010). Pengetahuan

Dasar Ilmu Pariwisata. Denpasar: Udayana Press
Undang-Undang Republik Indonesia Nomor 9 Tahun (2010) Tentang Kepariwisataan 